\title{
Fonoaudiologia educacional em tempos de pandemia de Covid-19
}

\author{
Educational speech therapy in Covid-19 pandemic times \\ Terapia educativa del habla en tiempos de pandemia Covid-19
}

Recebido: 28/12/2020 | Revisado: 29/12/2020 | Aceito: 05/01/2021 | Publicado: 06/01/2021

\author{
Elizamar Secondes do Nascimento Jucá \\ ORCID: https://orcid.org/0000-0002-4872-8733 \\ Faculdade de Ensino Superior do Piauí, Brasil \\ E-mail: elizasecondes@hotmail.com \\ Mariana Fonseca Silva Nascimento \\ ORCID: https://orcid.org/0000-0001-7275-2808 \\ Faculdade de Ensino Superior do Piauí, Brasil \\ E-mail: fgamarianafonseca@ hotmail.com
}

\begin{abstract}
Resumo
A pandemia em razão da rápida contaminação do vírus da Covid-19 afetou diretamente os setores da sociedade, a qual precisou se adaptar a novas formas em seus estilos de vida, principalmente na limitação de contatos sociais presenciais. No ambiente escolar não foi diferente, independentemente da faixa etária todos os alunos foram obrigados a se afastarem das salas de aula, necessitando que o processo de ensino aprendizado fosse alicerçado por meio da elaboração de novas estratégias. Nesse contexto, decorre a importância do profissional da fonoaudiologia educacional, a qual é responsável por prestar um apoio aos pais e professores, principalmente no que se refere a crianças que apresentam algum problema de fala e linguagem, por exemplo, e que compromete significativamente o seu aprendizado. O tema da pesquisa consiste em compreender como deve ocorrer a atuação do fonoaudiólogo educacional em tempos de pandemia do Covid-19. O objetivo principal da presente pesquisa consiste em analisar de que forma os fonoaudiólogos podem atuar no processo educacional em tempos de pandemia do Covid-19, o qual afastou, obrigatoriamente, os alunos das salas de aulas presenciais. Dentre os objetivos específicos: verificar problemas dos alunos no processo de ensino aprendizagem realizados via remota; identificar os principais programas que podem ser utilizados pelos fonoaudiólogos educacionais em prol do apoio aos educandose seus familiares e seus professores; Compreender as principais ações desenvolvidas pelos fonoaudiólogos educacionais. A problemática da pesquisa consiste no seguinte questionamento: como os fonoaudiólogos em tempos de pandemia do Covid-19 podem atuam em prol do desenvolvimento educacional de alunos que se encontram fora do ambiente escolar?Constatou-se por meio da pesquisa que a atuação do fonoaudiólogo é indispensável para o processo de ensino aprendizagem, pois sem o devido apoio desses profissionais a crianças que apresentam problemas em aspectos na linguagem, dificulta ainda mais o desenvolvimento educacional desses estudantes que se encontram fora das salas de aula.
\end{abstract}

Palavras-chave: Fonoaudiologia educacional; Covid-19; Educação.

\begin{abstract}
The pandemic due to the rapid contamination of the Covid-19 virus directly affected sectors of society, which had to adapt to new ways in their lifestyles, mainly in limiting face-to-face social contacts. In the school environment it was no different, regardless of the age group, all students were forced to leave the classrooms, requiring the teachinglearning process to be grounded through the development of new strategies. In this context, the importance of the professional of speech-language pathology education, which is responsible for providing support to parents and teachers, especially with regard to children who have a speech and language problem, for example, and which significantly compromises their learning. to understand how the educational speech therapist shouldperform in Covid19 pandemic times. The main objective of this research is to analyze how speech therapists canact in the educational process in Covid-19 pandemictimes, which obligatorily removed the students from the classroom. Among the specific objectives: to verify students' problems in the teaching-learning process carried out via remote; identify the main programs that can be used by educational speech therapists in support of students and their families and teachers; Understand the main actions developed by educational speech therapists. The research problem consists of the following question: how can speech therapists in times of the pandemic of Covid-19 act in favor of theeducational development of students who are outside the school environment? It was found through the research that the performance of the speech therapist is indispensable for the teaching-learning process, because without the proper support of these professionals to children who have problems in aspects of language, it makes even more difficult the educational development of these students who are abroad classrooms.
\end{abstract}

Keywords: Educational speech therapy; Covid-19; Education. 


\begin{abstract}
Resumen
La pandemia por la rápida contaminación del virus Covid-19 afectó directamente a sectores de la sociedad, que debieron adaptarse a nuevas formas en sus estilos de vida, principalmente en la limitación de los contactos sociales presenciales. En el ámbito escolar no fue diferente, independientemente del grupo de edad, todos los estudiantes se vieron obligados a abandonar las aulas, lo que exigió que el proceso de enseñanza-aprendizaje se fundamentara mediante el desarrollo de nuevas estrategias. En este contexto, la importancia del profesional de la educación en patología del habla y el lenguaje, que se encarga de brindar apoyo a los padres y maestros, especialmente con respecto a los niños que tienen un problema de habla y lenguaje, por ejemplo, y que compromete significativamente su aprendizaje. El tema de la investigación es comprender cómo debe desempeñarse el logopeda educativo en tiempos de pandemia de Covid-19. El objetivo principal de esta investigación es analizar cómo los logopedas pueden actuar en el proceso educativo en tiempos de pandemia de Covid-19. que obligó a sacar a los alumnos del aula. Entre los objetivos específicos: verificar los problemas de los estudiantes en el proceso de enseñanza-aprendizaje realizado vía remota; identificar los principales programas que pueden utilizar los terapeutas del habla educativos en apoyo de los estudiantes y sus familias y maestros; Comprender las principales acciones desarrolladas por los logopedas educativos. El problema de investigación consta de la siguiente pregunta: ¿cómo pueden los logopedas en tiempos de la pandemia del Covid-19 actuar a favor del desarrollo educativo de los estudiantes que se encuentran fuera del ámbito escolar? para el proceso de enseñanza-aprendizaje, porque sin el apoyo adecuado de estos profesionales a los niños que tienen problemas en aspectos del lenguaje, se dificulta aún más el desarrollo educativo de estos estudiantes que se encuentran fuera del aula.
\end{abstract}

Palabras clave: Logopedia educativa; Covid-19; Educación.

\title{
1. Introdução
}

A educação regular escolar é compreendida como aquela na qual as crianças se deslocam de suas casas para o estudo nas unidades escolares do território brasileiro, tanto da rede pública como da rede privada de ensino, ou seja, um ensino presencial, tanto de alunos como também de seus respectivos professores.

No entanto essa educação regular sofreu uma transformação repentina, pois no dia 6 de fevereiro do ano de 2020 é confirmado o primeiro caso de coronavírus no Brasil, no caso um homem de 61 anos que viajou à Itália, e deu entrada no Hospital Albert Einstein no dia anterior. Desse dia em diante os casos se multiplicaram em todo o mundo e houve a necessidade de afastamento dos estudantes das salas de aulas físicas e tendo que assistir aulas por meio de recursos digitais, utilizando, principalmente, a rede mundial de computadores (internet).

Conforme o Ministério da Saúde (2020) A Covid-19 é uma doença causada pelo coronavírus, denominado SARSCoV-2, que apresenta um espectro clínico variando de infecções assintomáticas a quadros graves. De acordo com a Organização Mundial de Saúde, a maioria (cerca de 80\%) dos pacientes com Covid-19 podem ser assintomáticos ou oligossintomáticos (poucos sintomas), e aproximadamente $20 \%$ dos casos detectados requer atendimento hospitalar por apresentarem dificuldade respiratória, dos quais aproximadamente 5\% podem necessitar de suporte ventilatório.

A pandemia do Covid-19 trouxe dentre suas consequências a necessidade de um isolamento social, e, dessa forma, houve além do prejuízo na economia global, trouxe consigo um prejuízo ainda incalculável,o afastamento dos alunos do ambiente escolar.

As consequências foram significativas nas escolas pois a maioria dos professores nunca tinham ministrado aulas por meio de uma tela de computador, e nem mesmo receberam essa capacitação, ocasionando vários problemas no processo de ensino-aprendizagem, como por exemplo os pais tendo que atuar como verdadeiros professores no ambiente doméstico.

Os problemas dos pais e dos professores ainda se tornaram mais graves pois não tiveram mais o suporte de equipes multidiciplinares que existiam nas escolas, como por exemplo psicólogos e profissionais da fonoaudiologia. Os fonoaudiólogos no ambiente escolar são extremamente importantes pois avaliam as principais limitações apresentadas pelo alunos, principalmente, no que se refere ao processo comunicativo e de linguagem. 
Esse período pandêmico tem demonstrado o quanto o fonoaudiólogo educacional contribui no ambiente educacional, principalmente no que se refere o apoio educacional aos alunos, aos seus respectivos familiares e aos professores.

O tema da pesquisa está relacionado com a atuação da fonoaudiologia educacional em tempos de pandemia da Covid19, procurando demonstrar como esses profissionais podem contribuir significativamente para o processo de ensino aprendizagem de alunos que se encontram em outro cenário de aprendizagem, fora das salas de aula.

O objetivo principal da presente pesquisa consiste em analisar de que formas os fonoaudiólogos educacionais podem atuar no processo educacional em tempos de pandemia do Covid-19, o qual afastou, obrigatoriamente, os alunos das salas de aulas presenciais.

Dentre os objetivos específicos ressaltam-se: verificar os principais problemas apresentados pelos alunos no processo de ensino aprendizagem realizados via remota; identificar os principais programas que podem ser utilizados pelos fonoaudiólogos educacionais em prol de proporcionar o devido apoio aos educandos e seus respectivos familiares e ao professor que de uma forma rápido viu o seu trabalho mudar drasticamente. Compreender as principais ações desenvolvidas pelos fonoaudiólogos educacionais.

A problemática da pesquisa consiste no seguinte questionamento: como os fonoaudiólogos em tempos de pandemia do Covid-19 podem atuam em prol do desenvolvimento educacional de alunos que se encontram fora do ambiente escolar?

No que se refere à metodologia, a presente pesquisa pode ser entendida como uma revisão bibiográfica ou literária, por meio da analise de várias fontes relacionadas ao papel da fonoaudiologia educacional no período em que o mundo passa por uma pandemia de Covid-19. Dentre as fontes ressaltam-se artigos científicos, materiais disponibilizados pelos conselhos de fonoaudiologia, e sites destinados a publicação de pesquisa cientificas, como o Scielo e o GOOGLE cadêmico, dentre outros.

Justifica-se a importância da pesquisa, em razão de um período pandêmico ter proporcionado uma mudança repentina na vida dos alunos, de seus familiares e da forma de como os professores devem atuar, ou seja, com estudantes, sendo obrigados a se afastarem das salas de aulas, em prol de evitar uma contaminação por um vírus que tem causado uma serie de mortes em todo o mundo. No entanto, há alunos que necessitam de uma atenção maior, como, por exemplo, aqueles que possuem algum problema de linguagem que dificulte o processo de ensino aprendizagem, principalmente, nos anos iniciais de alfabetização, necessitando, dessa forma uma atuação da fonoaudiologia educacional no apoio aos professores e informações aos seus familiares.

Salienta-se que a pesquisa é pertinente, podendo servir de base para futuras pesquisas para área da pedagogia e não menos importante para os profissionais de fonoaudiologia, psicologia e psicopedagogia principalmente, para aqueles mais voltados para a área educacional, demonstrando a devida importância que o fonoaudiólogo possui no processo de ensino aprendizagem.

\section{Referencial Teórico}

\subsection{Conceitos e ações desenvolvidas pelo fonoaudiólogo educacional}

A atuação profissional do fonoaudiólogo está descrita, de forma expressa, na Lei Federal n $\mathrm{n}^{\circ}$ 6.965/1981 e regulamentada pelo Decreto $\mathrm{n}^{\circ}$ 87.218/1982. De acordo com essa legislação, o fonoaudiólogo é “o profissional com graduação plena em Fonoaudiologia, que atua em pesquisa, prevenção, avaliação e terapia fonoaudiológica na área da comunicação oral e escrita, voz e audição, bem como em aperfeiçoamento dos padrões de fala e da voz".

$\mathrm{Na}$ construção de sua história, a Fonoaudiologia sempre estabeleceu vínculo estreito com a área da Educação. No entanto, sua atuação consolidou-se na área da saúde. Atualmente a Fonoaudiologia, assim como outras ciências da saúde, tem incorporado as propostas e conceitos relacionados à promoção de saúde, que incentiva o protagonismo e a autonomia do 
sujeito e da coletividade para agir em benefício de sua qualidade de vida. Inserido no contexto educacional, o desafio do fonoaudiólogo é colaborar, por meio do seu conhecimento, para o processo educativo.

A realidade educacional brasileira, os programas e políticas públicas, o princípio democrático da Educação para Todos, que favorece o processo de inclusão, bem como o entendimento de que os processos voltados à promoção de saúde estão atrelados à qualidade de ensino, caracterizam a importância da interlocução entre as áreas da Fonoaudiologia e da Educação (Oliveira e Schier, 2013).

O fonoaudiólogo, em parceria com a Educação, a partir de seus conhecimentos específicos relacionados à aquisição da leitura e escrita, linguagem oral, voz e audição, auxiliará a comunidade educacional no processo educativo. Nesse contexto, poderá atuar em redes públicas e no setor privado de ensino, em todos os níveis e modalidades, inclusive nas esferas administrativas. A ação profissional também poderá ocorrer em organizações do terceiro setor ou em empresas que prestam serviços educacionais. O profissional pode ser contratado como estatutário, nos moldes da CLT, ou como prestador de serviços.

Para atuar de forma ética e competente, o profissional, além de respeitar as normativas emanadas pelo Sistema de Conselhos Federal e Regionais de Fonoaudiologia e o Código de Ética Profissional, deve conhecer as políticas públicas de educação vigentes e outras normativas relacionadas à área da Educação, em particular a Constituição Federal, a Lei de Diretrizes e Bases da Educação Nacional, o Plano Nacional e Planos Estaduais e Municipais de Educação, Plano de Desenvolvimento da Educação, Políticas Públicas e Programas voltados à Educação e Saúde, Estatuto da Criança e do Adolescente e Declaração Universal dos Direitos Humanos e Bioética (CREFONO1).

A especialidade em Fonoaudiologia Educacional foi criada e reconhecida pelo Conselho Federal de Fonoaudiologia (CFFa) e tem como base, para a atuação, as recomendações presentes nas Resoluções $\mathbf{n}^{\circ}$ 309, do ano de 2005 . Nessa Resolução, observa-se que os aspectos da promoção de saúde assumem uma dimensão maior, em detrimento daqueles preventivos, embora ambos venham da medicina. Nesse sentido, esses avanços, originados de reflexões anteriores acerca das concepções que devem permear o trabalho do fonoaudiólogo em ambiente escolar ${ }^{2}$, contribuíram e, ainda contribuem, para pensar formas mais coerentes de atuação na escola. Esses novos fazeres devem considerar não apenas as manifestações fonoaudiológicas, mas, fundamentalmente, questões particulares dessa comunidade e da instituição escolar, começando pela sua função (Oliveira \& Schier, 2013).

Um dos principais objetivos da atuação do Fonoaudiólogo Educacional é colaborar com o processo educativo. Para isso, houve a necessidade da elaboração do Quadro 1, demonstrando os principais eixos de atuação desses profissionais em prol de maiores benefícios para o processo educacional: 
Quadro 1 - Eixos de atuação dos fonoaudiólogos educacionais.

\begin{tabular}{|c|c|}
\hline ação & ticas \\
\hline $\begin{array}{l}\text { Acolhimento da } \\
\text { demanda }\end{array}$ & $\begin{array}{l}\text { Identificar as principais demandas da equipe escolar, dos familiares e dos alunos, por meio de anális } \\
\text { individuais ou coletivas }\end{array}$ \\
\hline $\begin{array}{l}\text { Análise } \\
\text { situação } \\
\text { institucional }\end{array}$ & $\begin{array}{l}\text { Elencar aspectos fonoaudiológicos relacionados ao processo educativo; } \\
\text { Identificar fatores que possam afetar a saúde da coletividade escolar; } \\
\text { Observar o ambiente físico escolar em relação ao ruído, iluminação, acessibilidade, entre outros. }\end{array}$ \\
\hline $\begin{array}{l}\text { Proposição } \\
\text { estratégias }\end{array}$ & $\begin{array}{l}\text { Contribuir com a elaboração e o desenvolvimento do Projeto Político Pedagógico; } \\
\text { Planejar ações com o grupo gestor e a equipe técnica pedagógica; desenvolver ações educativas e } \\
\text { pedagógicas para apoio e efetivação da aprendizagem na perspectiva da inclusão e do respeito à } \\
\text { diversidade humana; } \\
\text { Oferecer suporte às atividades em sala regular e no Atendimento Educacional Especializado (AEE) de } \\
\text { acordo com as diretrizes específicas vigentes do Ministério da Educação; } \\
\text { Otimizar o processo de alfabetização e letramento destacando as interrelações dos processos de } \\
\text { linguagem, audição, fala, leitura e escrita; } \\
\text { Orientar atividades de promoção da comunicação oral e escrita a serem desenvolvidas pelos educadores; } \\
\text { Contribuir com o processo de alfabetização e letramento levando em conta as normativas vigentes para a } \\
\text { Educação Infantil e séries iniciais do Ensino Fundamental, as especificidades do processo educativo e as } \\
\text { diferentes metodologias educacionais; } \\
\text { Colaborar na adaptação dos espaços escolares e recursos pedagógicos, no que se refere a situações de } \\
\text { comunição e de aprendizagem; } \\
\text { Promover ações de saúde para a comunidade escolar, como por exemplo a saúde vocal e auditiva dos } \\
\text { professores e alunos; } \\
\text { Fomentar o diálogo entre secretarias de saúde, educação, assistência social, entre outras, contribuindo } \\
\text { para a integralidade de atendimento ao indivíduo e ao trabalho em rede; } \\
\text { Sensibilizar a comunidade escolar sobre as propostas a serem realizadas;>> propor atividades de } \\
\text { formação continuada para a equipe escolar; } \\
\text { Apresentar ações de educação permanente a fim de promover reflexões sobre a prática pedagógica e as } \\
\text { possibilidades de apoio familiar; } \\
\text { Intermediar campanhas que envolvam a otimização da comunicação e da aprendizagem no âmbito } \\
\text { educacional } \\
\text { Atuar em Núcleos de Apoio à Educação (NAE) e à Inclusão (NAI). }\end{array}$ \\
\hline $\begin{array}{l}\text { Implantação } \\
\text { propostas }\end{array}$ & $\begin{array}{l}\text { Estabelecer as prioridades de ações, de acordo as possibilidades e recursos de cada realidade; } \\
\text { Definir o planejamento estratégico, estabelecendo metas, prazos e responsáveis pela execução das ações; } \\
\text { Colaborar de forma integrada com o planejamento educacional; } \\
\text { Intermediar o diálogo entre familiares ou responsáveis, escola e os serviços de atendimento clínico } \\
\text { externo para encaminhamentos e acompanhamentos de alunos e professores; } \\
\text { Participar de reuniões com representantes das secretarias de educação e de outros órgãos, com a }\end{array}$ \\
\hline
\end{tabular}




\begin{tabular}{|l|l|}
\hline & comunidade ou grupos representativos desta, sempre que necessário; \\
\hline \multirow{3}{*}{$\begin{array}{l}\text { Monitoramento } \\
\text { de ações }\end{array}$} & $\begin{array}{l}\text { Realizar visitas itinerantes às unidades escolares, de maneira sistemática, a fim de verificar e } \\
\text { acompanhar a execução das ações planejadas e os indicadores educacionais; } \\
\end{array}$ \\
& $\begin{array}{l}\text { Garantir que todos os alunos recebam intervenções necessárias diante da diversidade escolar; } \\
\text { Avaliar sistemática e continuamente as ações desenvolvidas }\end{array}$ \\
\hline
\end{tabular}

Fonte: Conselho Federal de fonoaudiologia (2015).

A Fonoaudiologia Educacional é uma área de especialização da Fonoaudiologia voltada ao estudo e atuação para a promoção da Educação, em todos os níveis ou modalidade de ensino. A Fonoaudiologia tem muito a oferecer, como parte integrante da equipe pedagógica, agregando conhecimentos sobre a comunicação humana, que são de sua competência, assim como discutindo estratégias educacionais que possam favorecer o processo de ensino e aprendizagem. Sendo a educação escolar um direito de todos, a Fonoaudiologia auxilia na potencialização de práticas pedagógicas que contribuam para a melhoria do processo de aprendizagem e, consequentemente, da qualidade da educação brasileira (Nova Venecia, 2019).

A Figura 1 demonstra o ciclo referente a atuação do fonoaudiólogo no ambiente educacional:

Figura 1 - Esquema de atuação do fonoaudiólogo educacional.

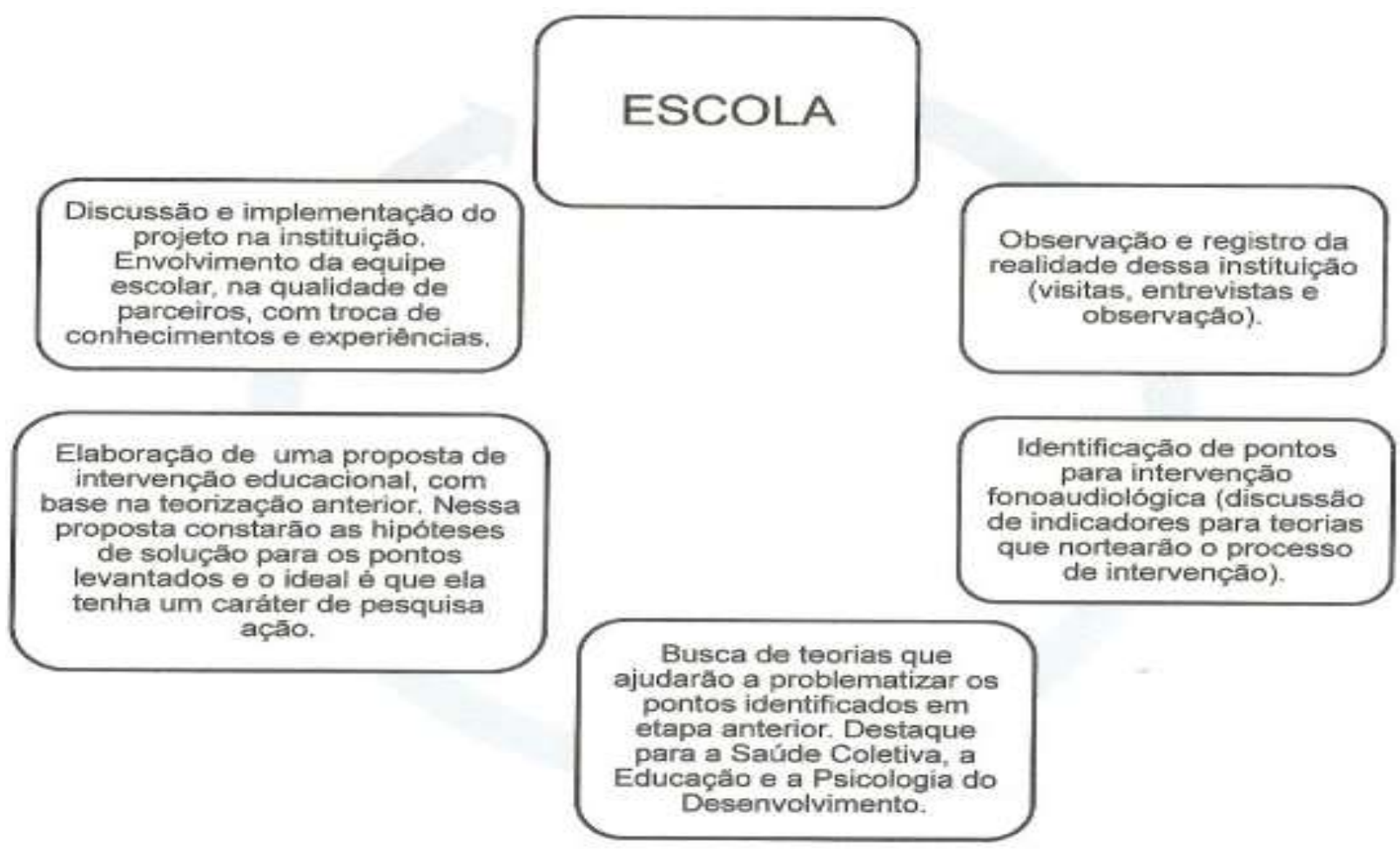

Fonte: Oliveira e Schier, (2013, p.2).

Por meio dessa imagem constata-se neste ciclo a grande importância da postura do fonoaudiólogo no âmbito escolar por meio da transmissão da disponibilidade de forma articulada com aspectos de interdisciplinaridade, conforme a estrutura e a rotina, encontradas na instituição escolar. É de suma importância lembrar que a escola é dotada de uma dinâmica própria e toda a gestão escolar deve estar envolvida em todas as mudanças que porventura possa ocorrer nessa dinâmica. 
Desse modo constata-se que o fonoaudiólogo educacional exerce vários papeis no seio da escola, ressaltando-se dentre suas funções a promoção de análises no contexto escolar para proporcionar sondagens na escrita em grupo e observar estratégias junto aos professores; atuações no processo de inclusão escolar de alunos que apresentem necessidades pedagógicas especiais; e auxílio na elaboração de técnicas que ofereçam ao estudante uma experiência satisfatória diante do medo de se comunicar de forma efetiva (Santos, 2015)

Em suma, infere-se que o fonoaudiólogo é o profissional que atualmente ocupa ou deve ocupar uma posição de destaque no que se refere ao atendimento de crianças diagnosticadas com alterações de leitura e escrita, contribuindo significativamente no processo educacional de ensino aprendizagem.

\subsection{Papel do fonoaudiólogo educacional em tempos de pandemia da Covid-19}

Com a ocorrência da pandemia da Covid-19, houve a necessidade dos estudantes, ressaltando-se as crianças, se mantiverem no processo de isolamento social em prol e prevenir que esse novo Corona Vírus fosse propagado mais rapidamente.

São diversas as consequências evidenciadas em razão desse cenário mundial, que mudou de forma brusca o estilo de vida dos seres humanos. Dentre os problemas ressalta-se a ansiedade e o estresse nas crianças que sem poder sair de casa, não podem interagir com os colegas em sala de aula. Diante de todo esse cenário e da mudança repentina das nossas vidas e rotinas, sintomas como estresse e ansiedade se tornaram cada vez mais comuns (Figueiredo, 2020).

$\mathrm{O}$ estresse e a ansiedade podem afetar significativamente a vida das crianças e consequentemente criará barreiras para o novo processo de aprendizagem, como aulas por meio da tela de um notebook, pois esses problemas afetam processos como a fala e a respiração. Um exemplo é o fato de pessoas que sofrem de ansiedade falarem de um modo mais célere e difícil de ser compreendido, em razão de alteração do padrão de respiração, e isso impacta diretamente na produção da voz. Desse modo os professores e os familiares dessas crianças sem o suporte do fonoaudiólogo educacional sentirão mais dificuldades para adequados processos educativos.

Somente com o auxílio de profissionais da fonoaudiologia educacional professores e pais serão mais capacitados para compreenderem como está se dando essa ansiedade, estresse e nervosismo, e consequentemente saberem as melhores maneiras de atuarem frente aos comportamentos dessas crianças (Antipoff, 2020).

Os fonoaudiólogos educacionais podem ajudar por meio da demonstração de exercícios que contribuem para reduzir o estresse e a ansiedade de crianças por meio de simples exercícios de respiração durante o período em que crianças se encontram em um isolamento social.

Além disso, quando os pais não se mostrarem capazes de compreender os métodos repassados pelos fonoaudiólogos em prol de reduzir as consequências de crianças que se encontram isolados longe do ambiente da sala de aula, esses profissionais podem se deslocar até os domicílios dessas pessoas para o devido acompanhamento.

No entanto durante esse acompanhamento domiciliar O Conselho Federal de Fonoaudiologia publicou a Resolução $\mathrm{CFFa} \mathrm{n}^{\circ}$ 577/2020 documento normativo que estabelece as principais medidas e cuidados nos atendimentos fonoaudiólogos em domicílio ou instituição de longa permanência, na vigência dos riscos de contágio pelo novo coronavírus (SARS-CoV-2). A determinação estipula que tais atendimentos deverão respeitar os decretos estaduais e municipais que disciplinam o distanciamento ou isolamento social (CREFONO1).

\subsection{Propostas a prática fonoaudiológica no contexto educacional}

Conforme Santana et.al (2020, p.2) são diversas os problemas na educação diante do contexto da pandemia da Covid19 e, consequentemente das necessidade de medidas de distanciamento social, conforme demonstrado no Quadro 2: 
Quadro 2 - Transformações no processo educacional devido a COVID-19.

\begin{tabular}{|l|l|}
\hline 1 & $\begin{array}{l}\text { Formação de Professores dos diferentes níveis de ensino através de Encontros Virtuais que envolvam temáticas } \\
\text { variadas: Comunicação e Ensino Remoto numa perspectiva acessível, Letramento Digital, saúde e tecnologia nas } \\
\text { plataformas digitais, saúde auditiva, dispositivos auditivos eletrônicos e uso das mídias digitais, desenvolvimento da } \\
\text { linguagem e aprendizagem e demais aspectos fonoaudiológicos. }\end{array}$ \\
\hline 2 & $\begin{array}{l}\text { Assessoria aos professores e participação de teleatividades que envolvam promoção de saúde e aprendizagem, } \\
\text { promoção de linguagem e letramento (via plataformas digitais); }\end{array}$ \\
\hline 3 & $\begin{array}{l}\text { Apoio aos familiares de alunos com diagnósticos de transtorno funcionais e público-alvo da educação especial via } \\
\text { encontros virtuais, visando um suporte para questões relacionadas à mediação familiar para a aprendizagem, recursos } \\
\text { de acessibilidade e comunicacionais durante as aulas não presenciais; }\end{array}$ \\
\hline 4 & $\begin{array}{l}\text { Grupo de orientação aos pais na Educação Básica (via plataforma digital); } \\
\text { Assessoria nas reuniões pedagógicas do ensino regular e da educação especial; }\end{array}$ \\
\hline 6 & $\begin{array}{l}\text { Participação no planejamento e nas aulas não presenciais do Atendimento Educacional Especializado (AEE) } \\
\text { juntamente com o professor de educação especial }\end{array}$ \\
\hline 7 & $\begin{array}{l}\text { Formação de Servidores do Setor de Acessibilidade da Biblioteca, Coordenadoria de Acessibilidade Educacional da } \\
\text { Universidade e Apoio Pedagógico da Universidade; }\end{array}$ \\
\hline 8 & $\begin{array}{l}\text { Teleatendimentos para grupos de alunos universitários com relação à promoção e dificuldades de linguagem escrita } \\
\text { (Oficinas de Letramento Digital). }\end{array}$ \\
\hline 9 & $\begin{array}{l}\text { Supervisão de estagiários que realizam mediações voltadas à linguagem escrita, aprendizagem e acessibilidade } \\
\text { educacional. }\end{array}$ \\
\hline
\end{tabular}

Fonte: Santana et.al (2020, p.2)

Observa-se o grande papel que possui o fonoaudiólogo educacional nesse período de pandemia, no qual a educação mundial tomou novos rumos no que se referem as suas metodologias. Agora os professores trocaram o pincel por aplicativos audiovisuais. Dessa forma o apoio de fonoaudiólogos aos professores e familiares, principalmente a alunos que apresentam algum tipo de diagnósticos de transtorno funcionais é imprescindível para um bom desenvolvimento do processo de ensino aprendizagem.

. Evidencia-se que o trabalho dos fonoaudiólogos educacionais é algo fundamental para uma atuação juntamente com a equipe escolar de modo ativo, acompanhando, o mais perto possível, o desenvolvimento de todos os alunos que necessitam de uma atenção especial, auxiliando os professores, assim como os coordenadores e os familiares da criança, levando sempre em consideração a peculiaridade de cada um dos alunos (Figueredo, 2020).

Desde modo, mesmo com a necessidade de um isolamento social o profissional da fonoaudiologia educacional não pode está distante no que se refere ao auxílio a professores e aos familiares dos alunos, pois mesmo que seja utilizada uma gama de recursos tecnológicos audiovisuais, os docentes e responsáveis pelos alunos não saberão lidar com as consequências severas causadas pela pandemia da Covid-19, como já ressaltado o alto grau de estresse e ansiedade, além da presença de mortes em várias famílias desses alunos.

Sem uma equipe multidisciplinar, na qual o fonoaudiólogo deve estar inserido, devem ainda estar presentes psicólogos, assistentes sociais, dentre outros profissionais, pois somente assim, os problemas referentes ao processo de ensino aprendizagem podem ser amenizados.

Os fonoaudiólogos educacionais devem estar presentes na elaboração de todas as atividades que são desenvolvidas para serem repassadas pelos alunos via remota ou teleaula. O monitoramento por parte desses profissionais deve ocorrer antes 
da aplicação dessas atividades como durante essas atividades, procurando evidenciar dessa forma, problemas que os professores sozinhos não conseguiriam identificar.

\subsection{A atuação do fonoaudiólogo educacional no acesso remoto e teleeducação}

O fonoaudiólogo educacional no que se refere ao acesso remoto está pautado em uma série de programas. Dentre eles ressalta-se o Programa Parents and Children Together

Esses programas envolvem a atuação dos fonoaudiólogos de uma forma bastante diversificada, servindo, tanto para atuação do fonoaudiólogo clínico, quando envolve a constatação de problema de crianças no que se refere ao processo de alteração do desenvolvimento de linguagem e fonologia e também, esses programas são plenamente utilizáveis pelo fonoaudiólogo educacional.

No âmbito educacional crianças que apresentam problemas de linguagem devem ser alvos de uma maior preocupação, e nesse contexto, o apoio aos professores ocorre justamente por meio da atuação de fonoaudiólogos. Por meio do acesso remoto e com a utilização de programas como o Parents and Children Together há a possibilidade da realização de um trabalho, desde ações voltadas a aspectos relacionados com a vulnerabilidade social de crianças até os problemas relacionados a neuro desenvolvimento, fazendo uma espécie de junção do trabalho realizado por professores na escola criando um elo com as famílias dos discentes (Oliveira e Schier, 2013).

Sempre deve haver essa ponte entre escola e família e o fonoaudiólogo educacional, por meio da utilização desses programas, denominados pacts, descritos na literatura, desde o ano de 1974, é um dos principais responsáveis pelo apoio tanto dos profissionais da educação como também aos familiares dos educandos.

O fonoaudiólogo educacional é muito atuante nos programas pacts principalmente em países localizados no continente europeu, ressaltando-se, países como o Reino unido, Itália e Turquia, assim como também na América do Norte, principalmente nos Estados Unidos da América.

No que se refere a Turquia, esse país tem como base a realização desses Pacts pelos fonoaudiólogos dentro do ambiente escolar, propriamente dito, com os pais recebendo uma série de orientações quanto ao desenvolvimento de aspectos da fala, aspectos da linguagem, além de aspectos cognitivos e linguísticos, por exemplo. Esses programas partem de um pressuposto relacionado com o desenvolvimento de crianças que apresentam problemas de fala e linguagem, os quais trazem consequências extremamente negativas no processo de ensino aprendizagem desses estudantes, principalmente nos anos iniciais de alfabetização (Seno e Capalini, 2019).

Os fonoaudiólogos juntamente com uma equipe, como psicólogos, por exemplo, devem utilizar esses programas Pacts em prol de uma intervenção precoce, compartilhada com os pais ou responsáveis e professores, com a possibilidade de proporcionar informações vias plataformas de orientações especificas direcionadas aos familiares e ao corpo docente.

Por meio da atuação dos fonoaudiólogos educacionais nesses programas pode haver uma maior preparação de pais responsáveis pelos alunos, em especial aqueles que apresentam algum problema nos aspectos de linguagem e que comprometem o processo de ensino aprendizagem.

Dessa forma os fonoaudiólogos educacionais devem auxiliar na produção de materiais que possibilitem informações aos pais e aos professores. Gama de orientações via remota, desde a preparação dos pais para uma melhor alfabetização das crianças em isolamento, demonstrando ferramentas tecnológicas que podem ser utilizadas em casa em prol do desenvolvimento do processo de alfabetização. Tudo deve ocorrer por meio de tutoria e monitoramento, relacionado com aspectos da leitura (Seno e Capalini, 2019). 
Por meio desses pacts pode haver uma intervenção direta dos fonoaudiólogos educacionais. A fonoaudiologia traz nesses programas o chamado home plans, montados para professores utilizarem em suas aulas em suma por meio do acesso remoto em ambientes virtuais de aprendizagem o fonoaudiólogo educacional é capaz de proporcionar a pais e mestres diversas orientações em vários aspectos, destacando-se: Letramento; Intervenção pedagógica, Programas informatizados de ensino de leitura e escrito por familiares, modelo one-to-one (para alunos com necessidades especiais), dentre vários outros.

Outro ponto de destaque da atuação do fonoaudiólogo educacional é a atuação por meio de recursos de teleeducação, a qual pode ser capaz de propiciar espécies de rotinas, semelhantes as realizadas nas escolar, pelos pais no ambiente doméstico.

$\mathrm{O}$ isolamento social, devido à pandemia do coronavírus, trouxe novas realidades para as famílias. Encarar o home office e as aulas em casa tem sido um desafio para os pais e nem sempre esse novo formato de lidar com a educação e o trabalho tem funcionado. Realizada pelo Instituto Nacional de Estatísticas Britânico (Office for National Statistics - ONS), uma pesquisa mostrou que 52\% dos pais disseram que os filhos estão tendo dificuldades para continuar estudando em casa. Além disso, 3 a cada 4 pais (77\%) acreditam que a falta de motivação é uma das razões para esse problema. Já 1 em cada 10 (9\%) dos pais relataram que a dificuldade dos filhos estava relacionada à falta de equipamentos e $43 \%$ a falta de apoio.

\subsection{Os reflexos na educação escolar pós-Covid}

No mundo inteiro, aproximadamente 190 países foram obrigados a fecharem suas escolas, deixando um número aproximado de 1,5 bilhão de crianças e adolescentes longe das salas de aula devido a pandemia de Covid-19. Desse modo, obrigatoriamente, houve a necessidade de criar novas alternativas em prol de dar prosseguimento na educação escolar regular, em especial, o desenvolvimento do ensino distância (UNESCO, 2020).

Essa educação por meio da utilização de dispositivos eletrônicos, associados à utilização da rede mundial de computadores (internet) tem proporcionado uma serie de desafios principalmente para os professores e para as famílias dos alunos.

A Educação a distância $(\mathrm{EaD})$ não pode ser a única solução, esta metodologia tende a exacerbar as desigualdades já existentes, que são parcialmente niveladas nos ambientes escolares, simplesmente, porque nem todos possuem o equipamento necessário. Se a meta for investir apenas em ferramentas digitais, certamente, contribuiremos para uma piora na aprendizagem dos alunos a curto e a médio prazos (Souza et. al., 2016).

Infere-se que todas as transformações que ocorre na sociedade, consequentemente trazem impactos para a educação. Se a sociedade atual está passando por uma crise advinda de uma pandemia não tinha a menor possibilidade de isso não trazer reflexos para o processo educacional no âmbito escolar.

Nós precisamos repensar o futuro da Educação, incluindo uma articulação apropriada entre o EaD e o Ensino presencial Até porque, muitos no Brasil não têm acesso a computadores, celulares ou à Internet de qualidade - realidade constatada pelas secretarias de Educação de Estados e municípios no atual momento - e um número considerável alto de professores precisou aprender a utilizar as plataformas digitais, inserir atividades online, avaliar os estudantes a distância e produzir e inserir nas plataformas material que ajude o aluno a entender os conteúdos, além das usuais aulas gravadas e online. $\mathrm{Na}$ pandemia, grande parte das escolas e das universidades estão fazendo o possível para garantir o uso das ferramentas digitais, mas sem terem o tempo hábil para testá-las ou capacitar o corpo docente e técnico-administrativo para utilizá-las corretamente (UNESCO, 2020 ).

A primeira consequência na educação refere-se ao fato de aumentar ainda mais a desigualdade social, pois há um grande risco de agravar ainda mais as desigualdades educacionais, pois as crianças saem do ambiente escolar e vão se isolar em suas residências, e caso seus familiares não possuam uma escolaridade mais alta, mais afluente, com a possibilidade de 
proporcionar condições de moradias dignas, com a presença de livros em casa, ou um acesso a um repertório cultural, logo será visto consequências negativas no que se refere ao déficit de aprendizagem, devido a perca da mediação dos professores no processo educativo (Queiroz, 2020).

Atualmente tanto escolas públicas como privadas, estão exagerando nas expectativas do que professores e familiares conseguem fazer. No entanto existem diferenças significativas entre as famílias em isolamento social. Algumas podem auxiliar os filhos a aprender mais do que outras. Fatores como a quantidade de tempo disponível para se dedicar aos estudos dos filhos, auxiliando-os com as aulas online - muitos pais estão em home office cumprindo horário laboral integral e outros tantos precisam trabalhar externamente para garantir a renda mensal -; as habilidades não cognitivas dos genitores; a possibilidade de acessar o material online; a quantidade de conhecimento inato dos pais - afinal, é difícil ajudar o filho se tiver de aprender algo estranho ao que se conheceu e aprendeu - , são questões a serem levados em conta quanto ao papel dos pais na Educação dos filhos em tempos de pandemia. Toda essa situação gerará um aumento da desigualdade na Educação e no progresso do estudante (Cifuentes, 2020).

Em todo o mundo estão sendo buscadas estratégias em prol de dar continuidade ao processo educacional, mas esse processo deve ser analisado em conformidade com a realidade social de cada localidade, pois há locais no mundo que nem sinal de televisão recebem, e a situação ainda é mais agravada quando se refere ao sinal de internet.

A Fonoaudiologia Educacional inserida na equipe pedagógica da escola cria e quebra as barreiras do aprender no intuito de proporcionar maior desempenho no processo diante das diversas situações em que o aluno apresente limitações.

\section{Metodologia da Pesquisa}

No que se refere a metodologia a pesquisa trata-se de um estudo de revisão de literatura, fundamentada por meio das bases de dados: Medline, Scielo Pubmed E Google Acadêmico. A revisão da literatura, também chamada "revisão bibliográfica", visa a demonstrar o estágio atual da contribuição acadêmica em torno de um determinado assunto. Ela proporciona uma visão abrangente de pesquisas e contribuições anteriores, conduzindo ao ponto necessário para investigações futuras e desenvolvimento de estudos posteriores.

Inicialmente foi realizada a busca ativa das palavras-chave no portal de descritores em ciências da saúde (decs). Com base no tema da contribuição da fonoaudiologia educacional em tempos de Covid. Foram analisados artigos, por meio dos seguintes descritores: Fonoaudiologia educacional; Educação; Covid-19. Posteriormente, foram analisados os artigos que mais interessavam no embasamento da pesquisa, usando os critérios de inclusão, ressaltando-se análise do artigo e sua contribuição sobre a temática da pesquisa, por meio da análise do resumo e da atualidade do estudo, assim como de exclusão, baseados na pergunta que norteia a revisão, mensuração dos desfechos de interesse, critério metodológico, idioma, tipo de estudo, tempo de busca, por meio de artigos publicados no período entre os anos de 2010 e 2020, disponibilizados na íntegra. O critério de exclusão da pesquisa pautou-se nas contribuições da fonoaudiologia educacional em tempos de Covid-19, sendo excluídas fontes que abordavam sobre a atuação em períodos ausentes de pandemia.

\section{Resultados e Discussão}

Após analisar as diversas teorias, presentes em artigos científicos, monografias, dissertações, livros e consultas em sítios eletrônicos, analisando principalmente revistas científicas, referente as principais contribuição da fonoaudiologia educacional em temos de Covid-19 chegou-se à vários resultados. 
Conforme se evidencia pela presente pesquisa bibliográfica, foram identificados diversos benefícios e contribuições dos profissionais da fonoaudiologia educacional em tempos de Covid-19.

Dentre os benefícios evidenciados ressaltam-se a atuação do fonoaudiólogo educacional nos programas pacts com os pais recebendo orientações quanto ao desenvolvimento de aspectos da fala, aspectos da linguagem, além de aspectos cognitivos e linguísticos, por exemplo (Seno \& Capalini, 2019).

Além disso, os fonoaudiólogos com uma equipe multidiciplinar, como psicólogos, utilizam pacts em prol de uma intervenção precoce, compartilhada com os pais ou responsáveis e professores, proporcionando orientações específicas direcionadas aos familiares e ao corpo docente.

Outra contribuição dos fonoaudiólogos educacionais consiste em uma preparação de responsáveis pelos alunos, principalmente para aqueles apresentam problema nos aspectos de linguagem e que comprometem o processo de ensino aprendizagem.

Os fonoaudiólogos educacionais devem auxiliar na produção de materiais que possibilitem informações aos pais e aos professores, demonstrando ferramentas tecnológicas que podem ser utilizadas em casa em prol do desenvolvimento do processo de alfabetização. Tudo deve ocorrer por meio de tutoria e monitoramento, relacionado com aspectos da leitura (Seno \& Capalini, 2019).

A fonoaudiologia traz nesses programas o chamado home plans, montados para professores utilizarem em suas aulas em suma por meio do acesso remoto em ambientes virtuais de aprendizagem o fonoaudiólogo educacional é capaz de proporcionar a pais e mestres diversas orientações em vários aspectos, destacando-se: letramento; intervenção pedagógica, programas informatizados de ensino de leitura e escrito por familiares, modelo one-to-one (para alunos com necessidades especiais), dentre vários outros.

Outro ponto de destaque da atuação do fonoaudiólogo educacional é a atuação por meio de recursos de teleeducação, a qual pode ser capaz de propiciar espécies de rotinas, semelhantes às realizadas nas escolas, pelos pais no ambiente doméstico.

\section{Considerações Finais}

Conforme a pesquisa é possível evidenciar vários impactos significativos na educação mundial, na qual os alunos foram privados da sala de aula para o isolamento de seus lares, perdendo dessa forma o convívio com seus colegas, e consequentemente criando problemas como o estresse a ansiedade que interferem diretamente no processo de ensino aprendizagem.

Nesse contexto evidencia-se a necessidade da importância do fonoaudiólogo educacional, pois as famílias e professores, muitas vezes se encontram desamparadas de apoio, pois problemas como a ansiedade interfere no modo de falar, e dessa forma, contribui para a redução de um feedback entre professor e aluno eu se encontram em contato somente por meio de uma tela de um computador.

Salienta-se que a grande disponibilidade de tecnologia como existe no mundo moderno, não significa o mesmo que dizer familiaridade com a tecnologia. Pois os professores, alunos e seus respectivos familiares estão padecendo com todas essas mudanças, e somente por meio da intervenção da escola, sem nenhum tipo de acompanhamento de outros profissionais, como é o caso do fonoaudiólogo educacional se tornara bastante dificultoso esse processo de ensino aprendizagem para todas as partes envolvidas. 
Constata-se que ainda são poucos os estudos referentes a fonoaudiologia educacional em tempos de Covid-19, principalmente em razão de esse período pandêmico ter ocorrido de forma brusca, não dando um tempo para que fossem estabelecidas metodologias em prol das novas rotinas educacionais, as quais saíram das salas de aula e se deslocaram para as salas de casa. Dessa forma espera-se que essa pesquisa seja mais uma fonte de pesquisa para auxiliar futuros acadêmicos relacionados com a educação, assim como professores e os familiares dos alunos.

\section{Referências}

Cifuentes, F. J. (2020). Consecuencias en los niños del cierre de escuelas por Covid- 19: el papel del gobierno, profesores y padres. Revista Internacional de Educación para la Justicia Social, Madrid, 9(3), 1-12.

CREFONO1. (2020). Conselho Regional de Fonoaudiologia da $1^{\circ}$ Região. Coronavírus: Atendimentos fonoaudiológicos em domicílio ou instituição de longa permanência. Cffa. http://crefono1.gov.br/coronavirus-atendimentos-fonoaudiologicos-em-domicilio-ou-instituicao-de-longa-permanencia/.

CREFONO3. (2020). Conselho Regional de Fonoaudiologia da $3^{\circ}$ Região. Fonoaudiologia Educacional em tempos de pandemia. Cffa. https://www.crefono3.org.br/view/fonoaudiologia-educacional-em-tempos-de-pandemia/2237/.

Antipoff, H. (2020). Pandemia da COVID-19: como a fonoaudiologia pode te ajudar? FHA. http://fha.mg.gov.br/noticia/educacao/07/2020/pandemia-daCovid-19-como-fonoaudiologia-pode-te-ajudar.

Figueiredo, L. (2020). Representações dos profissionais da educação acerca do fonoaudiólogo educacional. Distúrb Comun.

Oliveira, J. P., \& Schier, A. C. (2013). Suportes para a atuação em fonoaudiologia educacional. Rev. CEFAC. 15(3).

Queiroz, E. (2020). Os desafios da educação pós-pandemia, segundo Cláudia Costin. Fundação Edson Queiroz. https://www.unifor.br/-/os-desafios-daeducacao-pos-pandemia-segundo-claudia-costin

Santos, G. O. (2015). Fonoaudiologia Educacional: Desafios e Perspectivas. In: $8^{\circ}$ Encontro Internacional de Formação de Professores e $9^{\circ}$ Fórum Permanente de Inovação Educacional.

Secretaria Municipal de Educação. (2019). Superintendência de Educação. Fonoaudiologia na Escola, 2019. Espírito Santo: SEMEC/ES. 1. (Cadernos PDE).

Seno, M. P., \& Capellini, A. S. (2019). Nível de informação dos professores da educação especial sobre a fonoaudiologia educacional. Rev. psicopedag. 36(111).

Sousa, S.; Franco, V. S.; \& Costa, M. L. F. (2016). Educação a distância na ótica discente. Educação e Pesquisa, São Paulo, 42(1), 99-114. https://doi.org/10.1590/s1517-9702201603133875

UNESCO. (2020). A Comissão Futuros da Educação da Unesco apela ao planejamento antecipado contra o aumento das desigualdades após a COVID-19. Paris: Unesco. https://pt.unesco.org/news/comissao-futuros-da-educacao-da-unesco-apela-ao-planejamento-antecipado-o-aumento-das. 